\title{
Dietary habits during the postpartum period among a sample of lactating women in Sudan
}

\author{
Eshraga Abdallah Ali Elneim \\ Department: Nutrition and Food Science University of Hail, Saudi Arabia
}

\begin{abstract}
Period and the beginning of the end of the third stage of labor until 42 days after the birth, a critical period if that many deaths occur in this period, infected mother to many diseases. The device needs this time to nutritional care and aim of this study was to determine the pattern of daily food intake and dietary habits of practice in this period of women attending of Singa city maternal and child care centers at the end of the period of confinement to vaccinate their children. The study was conducted on 165 women. And applied the questionnaire was filled out by the interview. The results showed that the pattern of food consumption during the postnatal period focusing on eating meat and eggs 53.33\%, fish and chicken $73.93 \%$ and not eating fruits and vegetables and high energy snacks like porridge ring $30.30 \%$ and $57.57 \%$ and $29.94 \%$ date milk porridge with butter and your favorite foods $72.84 \%$ lamb Soup, $64.84 \%$ bird meat soup $72.84 \%$ tea ring with milk $90.90 \%$ alhargl grass with milk $90.90 \%$ hot milk with butter $57.57 \%$ and $75.75 \%$ prefer not to eat your vegetables and gain prominent causes of weight during this The period of appearance of the social bottom line results that good food in content of protein, carbohydrate, vitamins by frequency high power foods can cause obesity, which causes many health problems for women, and one of the most important recommendations of the moderation in eating food that contains sugar and animal fat, and increase physical activity to burn excess calories daily.
\end{abstract}

Keywords: food habits, Postpartum, lactating women, Sudan

\section{Introduction:}

Postpartum maternal health care influences the health of both the mothers and their children greatly. Like prenatal care, the postpartum health care that is typically provided during the six-week period after childbirth is very important to the mothers' health. ${ }^{1}$ In developing countries, over $60 \%$ of maternal deaths occur during the postpartum period. A great number of postpartum complications can be avoided. Physical as well as psycho-social problems can be detected early via an effective postpartum care. Effective postpartum care is essential to maximize survival of mothers and new born regardless of where a woman delivers. Ironically, in developing countries, about $70 \%$ of women do not receive any postpartum care. ${ }^{[2]}$.

In general, Western postpartum practices are based on the biomedical model, where by the role of the woman is less important than that of the physician. In contrast, the traditional non-Western perspective emphasizes that birth is part of a holistic and personal system, involving moral values, physical aspects, social relations, and relation to the environment. Postpartum health beliefs and practices among non-Western cultures are each distinct, but have many similarities . As such, it is important to increase one's intake of foods containing these nutrients to prevent risk of deficiencies. It is also important during these periods of the life span to not consume too much of each nutrient to reduce risk for levels of intake that may be harmful. Although meeting these increased nutrient requirements can and perhaps should be achieved by the consumption of appropriate amounts of foods in a balanced and varied diet, the use of dietary supplements may be beneficial in some situations [ 3 ].

Although the postpartum period serves as a critical time for weight-management interventions because weight retention and weight gain can be significant $(4 ; 5)$, few researchers have studied dietary behaviors characteristic to the postpartum period and strategies to effectively promote weight control among, exclusively breastfeeding (EB), mixed feeding (MF), or formula feeding (FF), overweight and obese women. Thus, examination of dietary behaviors and compliance with dietary guidelines would help determine nutritional characteristics and concerns specific to this group.

Gestational weight gain, pre-pregnancy weight, age, race, income and parity are also related to weight retention among postpartum women[ 6,7 ] reported predominantly white postpartum women consumed adequate dairy servings, but vegetable intake was not sufficient. Two studies have reported a higher consumption of fruits and vegetables and a lower fat intake among lactating women as compared to formula feeding women $[9,10]$. 


\section{Materials And Methods:}

Been using a sample of lactating women attending the maternal and child care centers at the end of the period of pre-trial detention to vaccinate children in city singe (in Sudan) sample included 165 women were mobilized questionnaire by interview which contained social and economic factors and the pattern of food consumption habits and foods avoided during the postpartum period and analysis of questionnaire to find the frequencies and percentages using the statistical program spss:

\section{Results}

\section{Results And Discussion}

Table 1 Socio-demographic characteristics of mothers $(\mathrm{n}=165)$

\begin{tabular}{|r|r|r|}
\hline Characteristic & Frequency & Percentage \\
\hline age groups & 25 & $15.15 \%$ \\
\hline (15-20 )eyers & 44 & $26.66 \%$ \\
\hline Mevel of education & 80 & $48.48 \%$ \\
\hline No formal schooling & 16 & $9.69 \%$ \\
\hline Primary & 25 & \\
\hline Secondary & 35 & $15.15 \%$ \\
\hline Tertiary & 61 & $21.21 \%$ \\
\hline Employment & 34 & $36.96 \%$ \\
\hline Government & $20.60 \%$ \\
\hline Private & 30 & \\
\hline Self-employed & 20 & \\
\hline Homemaker & 13 & $18.18 \%$ \\
\hline Less than 1000 & 102 & $12.12 \%$ \\
\hline $1000-2000$ pounds & $7.87 \%$ \\
\hline more than 2000 pounds & 63 & \\
\hline
\end{tabular}

Table 1 shows the socio-economic characteristics of respondents found $48,48 \%$ of the women in the age group (25-30 years) and the lowest was aged 30 years and above $9 \%$ and educational level of the Secretary-General $15,15 \%$,primary $21,21 \%$ were higher secondary education $36,96 \%$ and higher education $20,60 \%$, and a large proportion of women homemakers $61,81,18.18 \%$ workers in the government and $12 \%$ private and family income was above 50,30\% less than 1,000 pounds a month and 25,45\% income category (1000-2000) pounds in the month, and $24,24 \%$ more than 2000 pounds .

Table2 food consumption pattern during the puerperal period daily

\begin{tabular}{|c|c|c|c|}
\hline Foods & Total deal a day & Frequency & Percentage \\
\hline \multirow{4}{*}{ Fruits and vegetables } & Once & 100 & $60.60 \%$ \\
\hline & Twice & 15 & $9.09 \%$ \\
\hline & Three times & - & - \\
\hline & No special diet & 50 & $30.30 \%$ \\
\hline \multirow{4}{*}{ Milk } & Once & 5 & $3.03 \%$ \\
\hline & Twice & 40 & $24.24 \%$ \\
\hline & Three times & 120 & $72.72 \%$ \\
\hline & No special diet & - & - \\
\hline \multirow{4}{*}{ Eggs and meat } & Once & 22 & $13.33 \%$ \\
\hline & Twice & 43 & $26.06 \%$ \\
\hline & Three times & 88 & $53.33 \%$ \\
\hline & No special diet & 22 & $13.33 \%$ \\
\hline \multirow{4}{*}{ Fish and chicken } & Once & 122 & $73.93 \%$ \\
\hline & Twice & 43 & $26.06 \%$ \\
\hline & Three times & - & - \\
\hline & No special diet & - & - \\
\hline \multirow{4}{*}{ Date porridge } & Once & 56 & $33.93 \%$ \\
\hline & Twice & 44 & $26.66 \%$ \\
\hline & Three times & 50 & $30.30 \%$ \\
\hline & No special diet & 10 & $6.06 \%$ \\
\hline \multirow{4}{*}{ Fenugreek pills porridge } & Once & 95 & $57.57 \%$ \\
\hline & Twice & 35 & $21.21 \%$ \\
\hline & Three times & 12 & $7.27 \%$ \\
\hline & No special diet & 18 & $10.90 \%$ \\
\hline
\end{tabular}


Dietary habits during the postpartum period among a sample of lactating women in Sudan

\begin{tabular}{|c|c|c|c|}
\hline \multirow{4}{*}{ Millet flour porridge } & Once & 120 & $72.72 \%$ \\
\hline & Twice & 30 & $18.18 \%$ \\
\hline & Three times & 10 & $6.06 \%$ \\
\hline & No special diet & - & - \\
\hline \multirow{4}{*}{ Alasra fermented flour soup(elnsha) } & Once & 40 & $24.24 \%$ \\
\hline & Twice & 44 & $26.66 \%$ \\
\hline & Three times & 66 & $40 \%$ \\
\hline & No special diet & 15 & $9.09 \%$ \\
\hline \multirow{4}{*}{ Rice with milk } & Once & 54 & $32.72 \%$ \\
\hline & Twice & 81 & $49.09 \%$ \\
\hline & Three times & - & - \\
\hline & No special diet & 30 & $18.18 \%$ \\
\hline
\end{tabular}

Style food consumed during the puerperal period per day found that vegetables and fruits consumed once per day at $60.60 \% 9.09 \%$ address twice and lack of eating three times a day and $30.30 \%$ on $.3 .03 \%$ on daily food dairy once and $24.24 \%$ twice and the highest was three times 72.84 years\%. Eating eggs and meat $53.33 \%$ three times a day, $26.06 \%$ twice, and $13.33 \%$ once and $13.33 \%$ non-custom in daily consumption. the consumption of fish and chicken once a day $73.93 \%$ and twice $26.06 \%$. Date porridge eaten once $33.93 \%$ and twice $26.66 \%$ $30.30 \%$ three times a day.

And porridge ring consumed once per day $57.57 \%$ and twice $21.21 \%$ and three times $7.27 \%$ and $10.9 \%$ not allocated in the daily diet. Alasra soup and fermented with sugar ( elnsha) is consumed once per day $26.66 \%$ twice a day $26.66 \%$ and three times $40 \% 9.09 \%$ is considered a special diet in this period. And consumption of rice with milk once a day $32.72 \%$ and twice $49.09 \%$ to $18.18 \%$ is not considered a special food diet daily.

Table 3 Food are avoided during the postpartum period and why

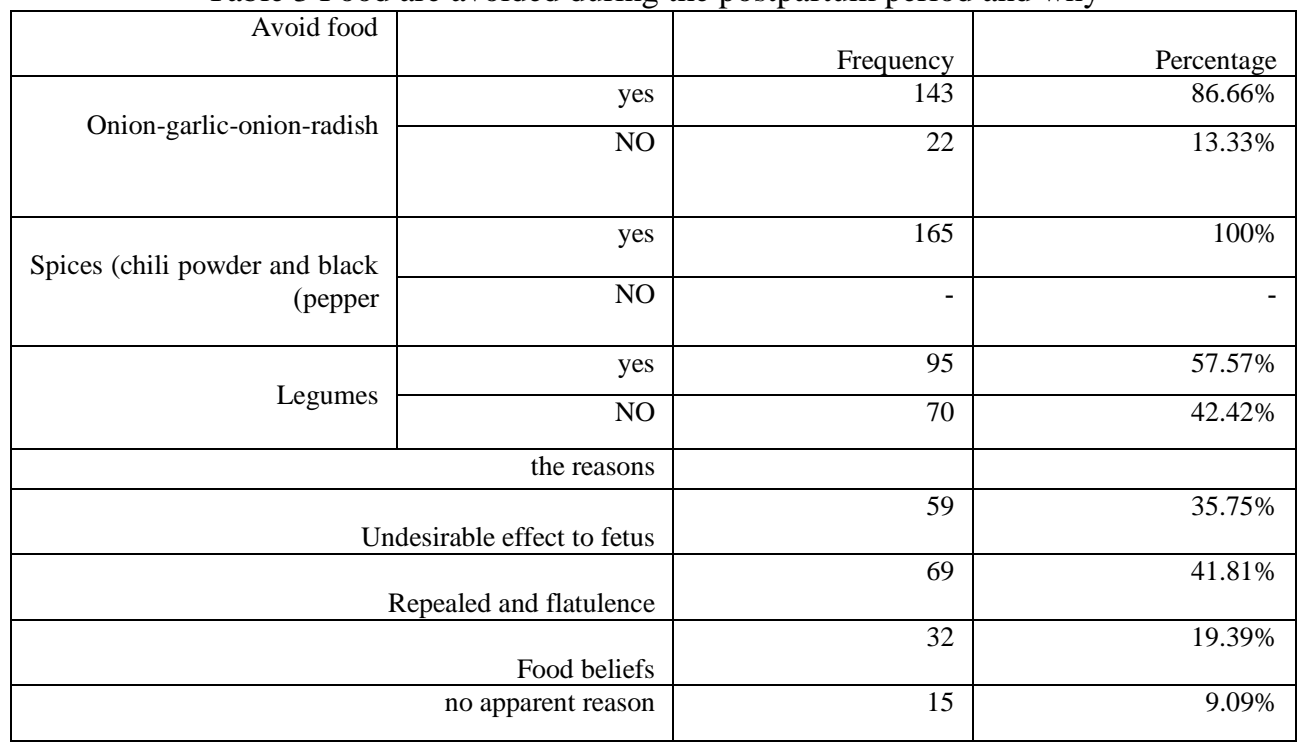

Foods to avoid during the puerperal period was onion and radish $87.62 \% 13.33 \%$ don't avoid it. Chili chili each sample to avoid eating legumes $57.57 \%, 100 \%$, not avoid 42.42 percent. Reasons for avoidance (not addressed): undesirable effect on fetus $35.75 \%$ intestinal flatulence $41.81 \%, 19.39 \%$ eating habits view 9.09 per cent, there is no reason to avoid these foods during the puerperal period.

Table 4 food consumption during the first day of birth

\begin{tabular}{|r|r|r|}
\hline Diet & Frequency & Percentage \\
\hline Foods rich in protein & 100 & $60.60 \%$ \\
\hline foods rich Energy - & 45 & $27.27 \%$ \\
\hline there is no special diet & 20 & $12.12 \%$ \\
\hline
\end{tabular}

The Joule shows the foods consumed on the first day of the birth and the protein-rich foods $60.60 \%$ Foods rich in energy for $27.27 \%$ there is no Private dining on the first day $12.12 \%$ 
Dietary habits during the postpartum period among a sample of lactating women in Sudan

Table 5 favorite foods during the postpartum period and the reasons

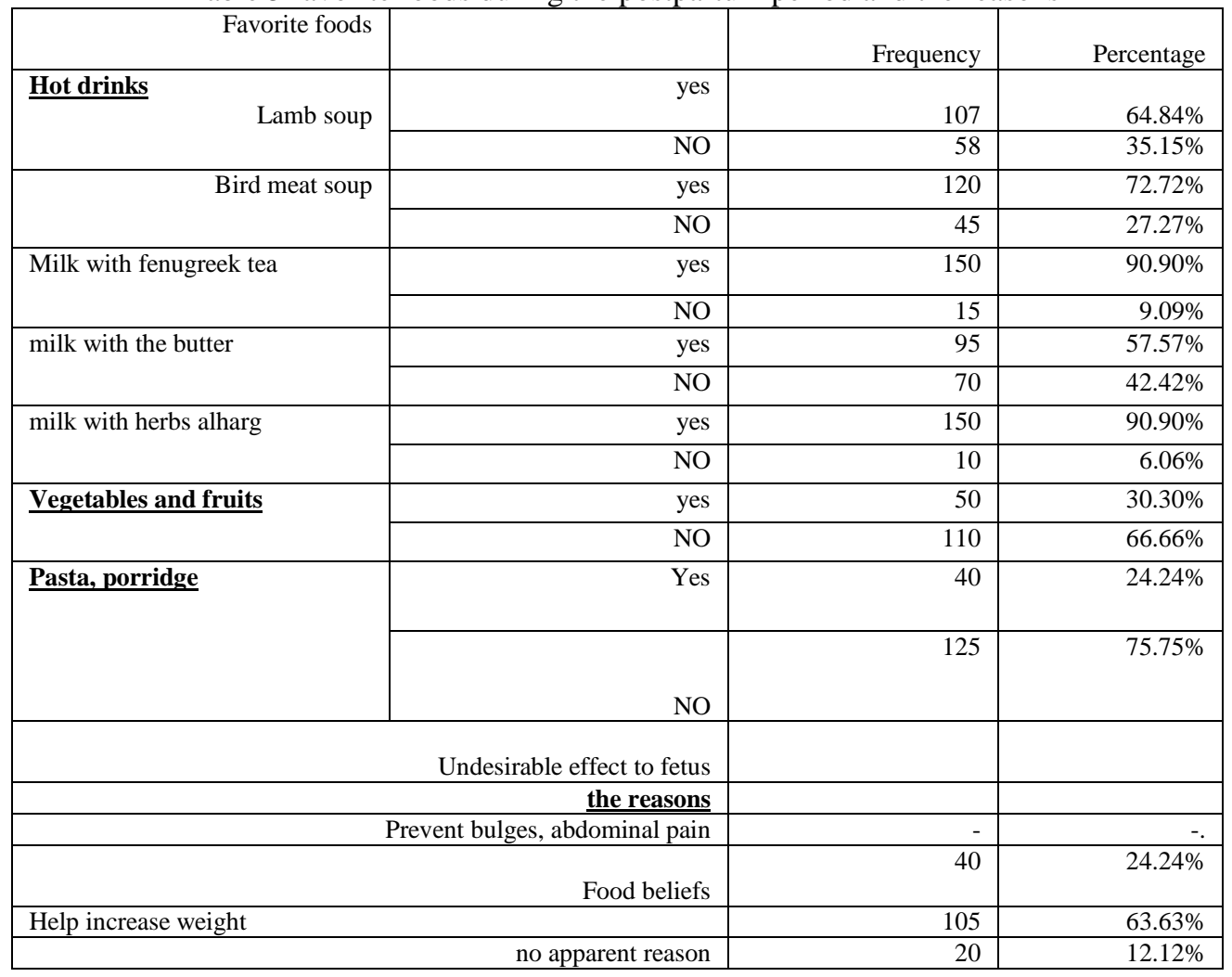

The table shows your favorite foods during the postpartum period and was eating Hot drinks

like soup lamb $64.84 \%$ prefer to eat while 35.15 percent prefer the soup birds favorite 72.84 years $\% 27.27 \%$ does not prefer. Fenugreek tea with milk is the preferred $90.90 \%$ and $15.9 \%$ no preference. hot milk with the butter animal $57.57 \%, 42.42 \%$ prefer not. milk $85.72 \%$ alhargl with Herb prefer eating and $6.06 \%$ prefer not. favorite vegetables and fruits for $30.30 \%$ and $66.66 \%$ do they prefer her favorite pastry $24.24 \%$ and 75.75 percent disfavored women. and reasons for preferring these foods were available at: $24.24 \%$ and $57.3 \%$ help in weight gain and there are reasons behind this preference $12.12 \%$ foods..

\section{Discussion}

The postpartum period is a very special phase in the life of a woman. Her body needs to heal and recover from pregnancy and childbirth, a good postpartum care and well balanced diet during the puerperal period is very important for her health. Several studies indicated that the incidences of postpartum health problems are high and these problems maybe have relation to traditional and unscientific dietary and behavior practices in the postpartum period [ 1 ]

In Sudan, there is a change in eating habits during the puerperal period in women. Table 1 shows the characteristics of the study sample and in the age group (25-30 years) $48.48 \%$ and a low level of education, $15.15 \%$, highest $36.96 \%$ secondary education and higher education, $20.60 \%$ a large proportion of women homemakers $61.81 \%$, the highest percentage of family income less than 1,000 pounds per month $50,30 \%$, and all these factors affect the pattern of food consumption during the postpartum period and social customs in Sudanese solidarity and cooperation between families with food in the form of gifts for women over the period, which To provide nutritional support for women in this critical period, the availability of food, especially high energy foods lead to obesity and these results against the results [15] that social support can influence the adoption of healthy behaviors during the puerperal period .

Table 2 shows the pattern of food consumption, so consumption of fruits and vegetables once a day $60.60 \%$ for women, 9.09 per cent, lack of consumption three times a day and $30.30 \%$ allocated in diet, eating habits, and we believe they cause flatulence and full scan recurring dairy $72.84 \%$ three times a day and eating meat and eggs three times a day, average $53.33 \%$ in daily food consumption 13.33 health risks, fish chicken once at $73.93 \%$ eat soups eaten as food not shared in the post Birth and after birth like date porridge eaten once $33.93 \%$ twice- $26.66 \%$ and $29.80 \%$ three times a day and consumes one ring on porridge $57.57 \%, 21.21 \%$ twice and three times $7.27 \%$ and $10.9 \%$ in the daily diet. Squeeze fermented with sugar soup (traditional local food) called starch consumed once every day $26.66 \%$ twice a day, $26.66 \%$ three times $40 \% 9.09 \%$ a special diet in this 
period. And consumption of rice with milk once\% 32.72 today and twice 49.09 and 18.18 per cent non-private daily diet due to high energy snacks, which enters into the composition of sugar, flour and milk, ghee and eaten as a meal of additional weight gain during this period, and this behavior is unhealthy because excess weight and obesity, which causes her future health risks in addition to this style of food helps lactating women to provide nutrients such as carbohydrates, proteins, minerals, vitamins, which supports Breastfeeding the feeding practices satisfactory during this critical period, and this is consistent with a study [14] As noted [19] to lactating women in the Sudan promotes high-protein food consumption practices, particularly the origins of the ring ( nasha) . Table 3 shows the foods to avoid during the postpartum period were onions and radishes $87.62 \%, 13.33 \%$ don't avoid it. Avoid peppers and chili all responders avoid eating legumes 57.57 100\%, do not avoid 42.42 percent. Causes of Heroes: an undesirable effect on the fetus $35.75 \%$, abdominal distension and intestinal $41.81 \%$, $19.39 \%$ eating habits and $9.09 \%$ there are no reasons to avoid these foods during the post-natal period, and these results demonstrate a lack of knowledge and reliance on legacy information in society, and these results are consistent with a study $[12,18]$

Table 4 shows foods consumed on the first day of birth and protein-rich foods $60.60 \%$ and energy rich food for $27.27 \%$ there is no custom food day $12.12 \%$ and protein-rich foods are usually good for mothers and children's health after birth while the energy rich food have addressed health hazards especially foods that enters in the composition of animal fats, sugar, this result agrees with the study [16 ] There are some excellent food and dangerous practices on the health of women following confinement in Saudi Arabia..

Table 5 shows the favorite foods during the postpartum period and hot drinks such as mutton soup $64.84 \%$ prefer to eat while prefer 35.15 percent prefer bird soup years $\% 27.2772 .84 \%$ favorite. Fenugreek tea with milk in my favorite $90.90 \%$ and $15.9 \%$ no preference. Hot milk with butter animal $57.57 \%, 42.42$ percent. Milk 85.72\% alhargl (herb), noted that the hot foods were more common in the food and favors prefer $6.06 \%$. Your favorite fruits and vegetables for $30.30 \%$ and $66.66 \%$ prefer women's favorite pastry $24.24 \%$ and $\% 75.75$. Reasons for preferring these foods available in: $24.24 \%$ and $57.3 \%$ help in weight gain, there are reasons for this preference foods because these foods prefer $12.12 \%$ dietary habits in the community are considered overweight manifestation of beauty.

\section{Conclusion:}

. The results indicate that food style for women in the postnatal period is characterized by excessive intake of food energy and frequency in use today and can say that the transition from pregnancy to childbirth may be linked to a negative impact on diet leading to obesity because of the habits, which can affect the health of women in the future.

\section{Recommendations:}

Antenatal clinic should be carried out sensitization programmers on nutrition and health care for pregnant women and their families. Some visits should include prenatal and postnatal visits to follow up and guide women to contemporary practices, thereby enabling women to correct eating habits. Furthermore, as well as future studies are necessary to explore the relationship between dietary practices and health outcomes for women. The study also recommends a study include chemical analysis of traditional foods in the study area.

\section{References:}

[1]. [Nian Liu, Limei Mao, Xiufa Sun, Liegang Liu, Ping Yao, Banghua Chen. The effect of health and nutrition education intervention on women's postpartum beliefs and practices: a randomized controlled trial BMC Public Health. 2009, 9: 45 Global Health Technical Brief.The Maximizing Access and Quality Initiative.[Online]http://www.maqweb.org/techbriefs/postp.shtml[Cited March 20, 201

[3]. 2009 American Society for Nutrition Subcommittee on Dietary Intake and Nutrient Nutrition during pregnancy. Washington, DC: National Academy Press, 1990

Supplements During Pregnancy.

[4]. Rooney BL, Schauberger CW. Excess pregnancy weight gain and long- term obesity: one decade later. Obstet Gynecol 2002;100:245-52

[5]. Gunderson EP, Abrams B. Epidemiology of gestational weight gain and body weight changes after pregnancy. Epidemiol Rev 2000;22:261-74

[6]. Lederman SA. The effect of pregnancy weight gain on later obesity. Obstet Gynecol 1993;82:148-55

[7]. Olson CM, Strawderman MS, Hinton PS, Pearson TA. Gestational weight gain and postpartum behaviors associated with weight change from early pregnancy to 1 y postpartum. Int $\mathrm{J}$ Obes

[8]. Holiday A. Durham .FOOD HABITS AND CHOICES, PHYSICACTIVITY,AND BREASTFEEDING AMONG OVERWEIGHT AND OBESE POSTPARTUM WOMEN DURHAM, HOLIDAY A, Ph.D. Food Habits and Choices, Physical Activity, and Breastfeeding Among Overweight and Obese Postpartum Women. (2008)

[9]. Walker LO, Freeland-Graves J. Lifestyle factors related to postpartum weight gain and body image in bottle- and breastfeeding women. J Obstet Gynecol Neonatal Nurs. 1998;27:151-60

[10]. George GC, Hanss-Nuss H, Milani TJ, Freeland-Graves JH. Food choices of low-income women during pregnancy and postpartum. J Am Diet Assoc. 2005;105:899-907

[11]. Holiday A. Durham Comparison of Dietary Intake of Overweight Postpartum Mothers Practicing Breastfeeding or Formula FeedingNational Center for Biotechnology Information, U.S. National Library of Medicine 8600 Rockville Pike, Bethesda MD, 20894 USA (2000) 
[12]. M Hishamshah, and others Belief and Practices of Traditional Post Partum Care Among a Rural Community in Penang Malaysia" INTERNE SCIENTIFIC PUBLICATIONS ISPUB.com / IJTWM/9/2/4210 2013

[13]. Mustapha, R.A.Nutrients Composition of Some Traditional Soups Consumed ByPostpartum Mothers In Nigeria IOSR Journal of Pharmacy and Biological Sciences (IOSR-JPBS) ISSN: 2278-3008. Volume 5, Issue 3 (Jan. - Feb.2013), PP 40-44 www.iosrjournals.org www.iosrjournals.org $40 \mid$ Page

[14]. Osman AK Dietary practices and aversions during pregnancy and lactation among Sudanese women. Journal of Tropical Pediatrics. $1985 \mathrm{Feb}$; 31(1):16-20.

[15]. BARBARA KAISER and CHANTAL RAZUREL Determinants of postpartum physical activity, dietary habits andweight loss after gestational diabetes mellitus Journal of Nursing Management, 2013, 21, 58-69

[16]. Samar k. Hafez 1\&2 and Sahar M. Yakout 1\&31 Early postpartum dietar practices among a group of Saudi women Journal of American Science, 2010;6(11) http://www.americanscience.orhttp://www.americanscience.org

[17]. Poh Bee Koon, Wong Yuen Peng \& Norimah A. Karim Postpartum Dietary Intakes and Food Taboos Among Chinese Women Attending Maternal and Child Health Clinics and Maternity Hospital, Kuala Lumpur Mal J Nutr 11(1): 1-21, 2005

[18]. Sabiha M. Abdalla Food habits during pregnancy and lactation in Iraq University of Basrah, Basrah, Iraq e old United Nations University website. Visit the new site at http://unu.edu

[19]. Osman AK Dietary practices and aversions during pregnancy and lactation amon Sudane women journal of Tropical pediatrics . 1985 Feb. 31(1):16-20 